\title{
READINESS OF HEALTH FACILITIES TO PROVIDE INSTITUTIONAL DELIVERY CARE: A STUDY BASED ON BANGLADESH HEALTH FACILITY SURVEY 2017
}

\author{
Gaylan Peyari Tarannum Dana ${ }^{1}$ \\ Sawkia Afroz ${ }^{2}$
}

\begin{abstract}
The burgeoning rise of preventable reasons of maternal deaths is highlighted as a prime concern for maternal health in Bangladesh. The main objective of this study was to assess the preparedness of health facilities to provide institutional delivery in Bangladesh. This study utilized data from the 2017 Bangladesh Health Facility Survey. Readiness of 1600 health facilities were measured using the service availability and readiness assessment manual of the World Health Organization. Health facilities were classified into public, private facilities, and NGO. Among the 1600 health facilities measured in this study, public facilities showed higher availability of normal delivery readiness whereas private facilities showed higher availability of caesarean delivery readiness. This study found a significant geographical variation in terms of readiness of health facilities to provide institutional delivery. In order to minimize the burden of preventable maternal deaths in Bangladesh, urgent improvement in all levels of health facilities, especially in health facilities of rural areas it is prerequisite to achieve the maternal health related targets of SDGs.
\end{abstract}

Keywords: Delivery, Health facilities, Readiness, Bangladesh

\section{Introduction}

Many women of developing countries die because of problems arise from pregnancy and delivery in spite of improving access to maternal health services, which is the fundamental issue of global safe motherhood initiative (Anjomshoa \& Mousavi, 2014). According to World Health Organisation [WHO] (2015), four in ten maternal deaths befall in less developed and developing countries which is

1 Gaylan Peyari Tarannum Dana is Associate Professor, Department of Population Sciences, University of Dhaka, Bangladesh. Email: tarannum_dps@du.ac.bd [Corresponding Author]

2 Sawkia Afroz is Lecturer, Department of Population Sciences, University of Dhaka, Bangladesh. Email: sawkia.afroz@du.ac.bd

Social Science Review [The Dhaka University Studies, Part-D], Vol. 38, No. 1, June 2021 DOI: https://doi.org/10.3329/ssr.v38i1.56522 
avoidable only by ensuring safe motherhood ensured. Therefore, safe motherhood can be ensured through Institutional delivery, and it is an important approach to minimize the loads of maternal mortality (Assefa, Alemayehu, \& Debie, 2018). In this regard, a sustainable, adequate, effective, quality, accessible, available, and affordable healthcare system as well as universal use of maternal healthcare services are essential preconditions. International communities including Bangladesh have been committed to decrease maternal deaths to less than 70 per 100,000 live births to achieve Sustainable Development Goal 3 (Target 3.1) by 2030 (United Nations, 2015).

Bangladesh has made tremendous progress in decreasing maternal death from 322 to 196 per 100,000 live births during 2001-2010, however the rate has remained stagnant since 2010, because health facilities failed to provide quality maternal healthcare educing maternal mortality and (NIPORT, icddr,b, \& Measure Evaluation, 2020b). In Bangladesh, most of the maternal deaths occur due to haemorrhage, eclampsia and preeclampsia, abortion and direct as well as indirect causes (NIPORT, icddr,b, \& Measure Evaluation, 2017). Even though access to and utilization of quality institutional delivery is an important component of reducing maternal mortality and morbidity. Considering every pregnancy risky pregnancy, the situation of institutional delivery in terms of both normal and Csection delivery has been improved over the period of times in Bangladesh. Since last two decades the rate of institutional delivery care has increased by $45 \%$ (4\% in 1993-1994 and 49\% in 2017-18) (NIPORT, icddr,b, \& Measure Evaluation, 2020a) though it falls short of the targets of $4^{\text {th }}$ Health, Population and Nutrition Sector Programme (HPNSP), 65\% by 2022 (MOHFW, 2017) and Sustainable Development Goals (SDGs), 98\% by 2030 (NIPORT, icddr,b, \& Measure Evaluation, 2020b) regarding institutional delivery. Delivery care rate by Csection also has increased by 30\% (3\% in 1999-00 and 33\% in 2017-18) (NIPORT, icddr,b, \& Measure Evaluation, 2020a). Nevertheless, the regional inequalities in the allocation of health facilities (Anjomshoa \& Mousavi, 2014) are a persisting challenge for Bangladesh (NIPORT, icddr,b, \& Measure Evaluation, 2020b). Moreover, inhabitants of rural areas are less probably to utilize health facility-based delivery care than the inhabitants of urban areas (45\% vs $63 \%$ ) and to receive delivery care by C-section (29\% vs 44\%) (NIPORT, icddr,b, \& Measure Evaluation, 2020a). Seventeen percent of Bangladeshi women experienced complication related to obstructed labour whilst young women mostly suffer from it (NIPORT, icddr,b, \& Measure Evaluation, 2020a). 
Demand for institutional delivery mostly depends on the availability and readiness of the service which is an important determinant of utilization of delivery care (Muchie, 2017). Besides improvement of maternal healthcare highly relies on well-equipped institutional delivery system of the facilities (Donabedian, 1969). Along this line of thinking, addressing the gaps in availability and preparedness of health facilities is an important factor to achieve the goal to reduce maternal mortality. The World Health Organization (WHO) defined 'service readiness' as the comprehensive capacity of health facilities to provide services related to healthcare and 'availability' as the 'physical provision of health-care services' which means availability of basic appliances, amenities, tools and instruments, standard precautions, laboratory diagnostics and medicines (WHO, 2015). In acknowledgement of the importance of institutional delivery and obstetric complications Bangladesh has applied essential health service package which included the emergency obstetric care as its core component to encourage institutional deliveries but accessibility of poor women to this service, has been highlighted as an important barrier (Ensor et al., 2002; Wichaidit et al., 2016). Emergency obstetric care has been distinguished between basic emergency obstetric care (BEmOC) that is non-surgical and comprehensive emergency obstetric care (CEMOC) including C-section and blood transfusion (Sikder et al., 2015). Provision of emergency obstetric care is a convenient approach in managing those cases of developing countries (De Bernis et al., 2000).

The healthcare system of Bangladesh consists of four body of authorities: government, profit based private sector, non-profit based private sector, and the international development organizations (Joarder, Chaudhury, \& Mannan, 2019). Public sector consists of community level, primary level, secondary level healthcare and tertiary level healthcare and governed by the Ministry of Health and Family Welfare (DGHS, 2020). Private healthcare consists of profit based private sector, non-profit based private sector, and informal providers. In accordance with 2019 Health Bulletin developed by Bangladesh's Ministry of Health and Family Welfare, all 19 Government medical college hospitals, 61 district and general hospitals, 419 upazila health complexes, 68 maternal and child welfare centres, 5 other government hospitals, 1 private medical college hospital, 46 NGO hospitals and 61 private clinics are set down to supply emergency obstetric care (DGHS, 2020). Therefore, for reducing the maternal mortality in Bangladesh it is essential to increase the utilization of facility delivery. 
A wide-ranging study has identified various factors that have impact on institutional delivery (Exavery et al., 2014; Gabrysch \& Campbell, 2009; Kitui, Lewis, \& Davey, 2013; Montagu, Yamey, Visconti, Harding, \& Yoong, 2011; Moyer, Dako-Gyeke, \& Adanu, 2013). While other studies generated insights on health system (Kaur, Franzen, Newton-Lewis, \& Murphy, 2019; Savedoff, de Ferranti, Smith, \& Fan, 2012) and utilization of maternal healthcare services (Gitobu, Gichangi, \& Mwanda, 2018; Manthalu, Yi, Farrar, \& Nkhoma, 2016; Nguyen et al., 2012; Steenland et al., 2017), to the authors best of knowledge very few studies focused on the supply side that investigates the readiness of health facilities to distribute institutional delivery care in Bangladesh. Besides rural-urban disparities regarding availability of institutional delivery care have not been assessed. However, earlier studies suggested that these records may exaggerate the actual scenario of availability and readiness of emergency obstetric services because inequalities by regions and health facility types are still highly prominent in Bangladesh (Anwar, Kalim, \& Koblinsky, 2009; Mridha, Anwar, \& Koblinsky, 2009). Also, the Demographic and Health Survey Program's Service Provision Assessment (SPA) has been used to produce structural capacity of health services rather than monitoring the level of actual service delivery (Wang, Mallick, Allen, \& Pullum, 2019). Therefore, objective of this study is to assess the service availability and readiness of health facilities regarding institutional delivery care in Bangladesh.

\section{Methods}

\section{Data Source}

This study is based on analysis of secondary data from Bangladesh Health Facility Survey 2017 (National Institute of Population Research and Training \& ICF, 2019). Study design for the Bangladesh Health Facility Survey 2017 was cross-sectional with a stratified random sample of 1600 health facilities handled by the government, NGO, and private sectors in Bangladesh. This survey was designed to collect information about the availability of services and readiness of health facilities in terms of family planning, maternal health, child health, noncommunicable diseases (diabetes and cardiovascular disease) and communicable diseases (tuberculosis). The survey also collected data on availability of manpower, basic services and logistics supports including essential drugs, equipment, laboratory services and infection control mechanisms of health facilities. 


\section{Variables}

In total, 1600 health facilities were incorporated to measure the readiness score of normal and caesarean delivery service. Availability of human resource, equipment, diagnosis services and essential medicine were assessed following the WHO-SARA scoring guideline for health service readiness for both normal and caesarean delivery. Readiness score has been computed as the mean availability of service-specific tracer items in four domains: staff, guideline, equipment, and medicines. All the readiness indicators for each item under normal and caesarean delivery domain were recoded as binary variables, taking value " 1 " for the availability of tracer item and "2" for the absence of items in the facility. Among the tracer item Delivery Pack was created by aggregating all the delivery equipment (Delivery pack OR cord clamp, episiotomy scissors, scissors/blade to cut cord, suture material with needle, and needle holder) and for the Anaesthesia equipment (Anaesthesia machine; Resuscitator bag and mask-adult and paediatric; Tubings and connectors to connect to the endotracheal tube; Intubation set adult and paediatric (Oropharyngeal airway, laryngoscope, Magill's forceps, endotracheal tubes, stylet). Delivery care (Normal and Caesarean) has been considered as dependent variable for this study. We have created both the dependent variables, Comprehensive Caesarean Delivery ( 7 obstetric signal functions (yes, no), caesarean section (yes, no) and blood transfusion (yes, no)) and Normal Delivery (staff and guideline (yes, no), equipment (yes, no) and essential medicines (yes, no). on the other hand, the independent variables were divisions, place of residence (urban/rural) and health facility type (Public, NGO, and Private Facilities).

\section{Statistical Methods}

The study used both the datasets (facility inventory and provider interview) of Bangladesh Health Facility Survey 2017. To assess the readiness of health facilities that provide delivery services in Bangladesh the WHO-SARA guideline was followed for calculating health facilities means and standard deviation $( \pm \mathrm{SD})$ of all domain scores for normal and caesarean delivery related service readiness index followed by logistic regression. Normal and caesarean delivery servicerelated readiness index was based on the mean availability of items as percentage within that domain. Additionally, logistic regression analysis was used to explain service readiness by adjusting for health facility type, region, and place of 
residence (urban/rural). Beta coefficient $(\beta) \geq 1$ from regression models identifies favourable changes in readiness index and vice-versa. The outcome variables were log-transformed before analysis to mark the non-normal distribution of residuals detected in the regression models. A two-sided p-value below 0.05 was considered significant. Data were not weighted during the analysis, and all the results were summarized and presented as frequencies and percentages by facility type. SPSS version V.21 is used for all analyses.

\section{Result}

Findings of general service readiness and mean domain score of basic amenities, basic equipment, and standard precautions for infection prevention for health facilities categories (public, NGO, and private facilities) are shown in Table 1. Overall result demonstrates that public facilities possessed a higher availability of items in all domains of general service readiness than other health facilities. The mean domain scores for basic amenities, basic equipment, and standard precautions for infection prevention for public facilities, were $74.2( \pm$ SD 10.76), $82.1( \pm$ SD 2.40$)$ and $81.7( \pm$ SD 5.50) respectively. NGO facilities had the lowest mean domain score for all domains of general service readiness.

Table 1: Status of General Service Readiness of Health Facilities for Delivery Services

\begin{tabular}{|lccc|}
\hline & $\begin{array}{c}\text { Public } \\
\text { Facilities } \\
\mathbf{\%}\end{array}$ & $\begin{array}{c}\text { NGO } \\
\text { Facilities } \\
\mathbf{\%} \\
(\mathbf{n = 1 3 3 8})\end{array}$ & $\begin{array}{c}\text { Private } \\
\text { Facilities } \\
\mathbf{\%}\end{array}$ \\
\cline { 2 - 4 } & 83.0 & 9.6 & 8.4 \\
Power (National Grid) & 57.7 & 16.9 & 25.4 \\
Generator & 83.2 & 8.4 & 8.5 \\
Water Source & 83.7 & 8.7 & 7.6 \\
Adequate sanitation facilities & 61.6 & 14.7 & 23.7 \\
Communication equipment & 77.7 & 11.6 & 10.6 \\
Access to computer with internet & 72.5 & 8.2 & 19.3 \\
Emergency transportation (ambulance) & $\mathbf{7 4 . 2}$ & $\mathbf{1 1 . 2}$ & $\mathbf{1 4 . 8}$ \\
\hline Mean Domain Score of Basic Amenities $( \pm$ SD) & $\mathbf{( 1 0 . 7 6 )}$ & $\mathbf{( 3 . 4 3 )}$ & $\mathbf{( 7 . 7 7 )}$ \\
\hline Basic Equipment & \multicolumn{3}{c}{} \\
Adult Scale & 83.00 & 9.2 & 7.8 \\
\hline
\end{tabular}




\begin{tabular}{|c|c|c|c|}
\hline Child Scale & 81.5 & 9.9 & 8.7 \\
\hline Thermometer & 83.1 & 9.1 & 7.8 \\
\hline Stethoscope & 84.6 & 8.2 & 7.2 \\
\hline Light Source & 77.6 & 11.9 & 10.5 \\
\hline Blood Pressure Apparatus & 82.5 & 5.00 & 12.5 \\
\hline $\begin{array}{l}\text { Mean Domain Score of Basic Equipment } \\
( \pm \text { SD })\end{array}$ & $\begin{array}{c}82.1 \\
(2.40)\end{array}$ & $\begin{array}{c}8.9 \\
(2.27)\end{array}$ & $9.1(2.03)$ \\
\hline \multicolumn{4}{|l|}{ Standard Precautions for Infection Prevention } \\
\hline Soap & 79.7 & 5.9 & 14.5 \\
\hline Running Water & 81.1 & 5.7 & 13.1 \\
\hline Alcohol Based Hand Disinfectant & 72.9 & 7.2 & 19.8 \\
\hline Latex Gloves & 82.8 & 5.4 & 11.8 \\
\hline Sharps Container & 84.1 & 5.5 & 10.4 \\
\hline Waste Receptacle & 89.6 & 4.5 & 6.00 \\
\hline $\begin{array}{l}\text { Mean Domain Score of Standard Precautions } \\
\text { for Infection Prevention }( \pm \text { SD) }\end{array}$ & $\begin{array}{c}81.7 \\
(5.50)\end{array}$ & $\begin{array}{c}5.7 \\
(0.88)\end{array}$ & $\begin{array}{c}12.6 \\
(4.58)\end{array}$ \\
\hline
\end{tabular}

Readiness index scores of facilities with respect to services for normal delivery is presented in table 2. Among the selected health facilities availability of staff for normal delivery in public facilities was high (78.6\%) compared with private facilities (15.8\%) and NGO facilities (5.5\%). The status of guidelines on BEmOC and trained staff for Beck were also high in public facilities $(84.1 \%$ and $83.5 \%)$ than those of private facilities $(5.3 \%$ and $7.4 \%)$ and NGO facilities $(10.6 \%$ and $9.1 \%$ ) respectively. Mean domain score for staff and guidelines for public health facilities $(82.5 \%)$ was much better compared with private facilities $(8.9 \%)$ and NGO facilities $(8.6 \%)$. In public facilities the mean domain score for equipment was $77.4 \%$ and in private health facilities it was $16.1 \%$ and in NGO facilities it was $6.5 \%$. Although mean score for availability of medicines in public health facilities was high $71.2 \%$ compared with private facilities (20.9\%) and NGO facilities (7.9\%). But in the readiness index scores for normal delivery the mean domain score for medicine was low in public health facilities compared with other two domains (staff and guidelines and equipment) of the public facilities. Considering all the three domains such as staff and guidelines, equipment, and medicine the readiness of public facilities was comparatively better in these respects. 
Table 2: Readiness Index Scores Specific to Services for Normal Delivery and Domain Scores by Facility

\begin{tabular}{|c|c|c|c|}
\hline Staff and Guidelines & $\begin{array}{c}\text { Public } \\
\text { Facilities \% } \\
(\mathbf{n}=1338)\end{array}$ & $\begin{array}{c}\text { NGO } \\
\text { Facilities } \\
\%(n=130)\end{array}$ & $\begin{array}{c}\text { Private } \\
\text { Facilities \% } \\
(\mathbf{n}=132)\end{array}$ \\
\hline $\begin{array}{l}\text { Availability of staff for normal } \\
\text { delivery }\end{array}$ & 78.6 & 5.5 & 15.8 \\
\hline Training in new-born care & 82.7 & 9.7 & 7.6 \\
\hline Guidelines on BEmOC & 84.1 & 10.6 & 5.3 \\
\hline Trained Staff for BEmOC & 83.5 & 9.1 & 7.4 \\
\hline $\begin{array}{l}\text { Staff trained in essential } \\
\text { childbirth care }\end{array}$ & 83.4 & 8.3 & 8.3 \\
\hline $\begin{array}{l}\text { Mean Domain Score of Staff and } \\
\text { Guidelines }( \pm \text { SD })\end{array}$ & $82.5(2.21)$ & $8.6(1.95)$ & $8.9(4.03)$ \\
\hline \multicolumn{4}{|l|}{ Equipment } \\
\hline Sterilization equipment & 81.2 & 9.8 & 8.9 \\
\hline Examination light & 77.7 & 6.4 & 15.9 \\
\hline Manual vacuum extractor & 74.1 & 5.5 & 20.4 \\
\hline $\begin{array}{l}\text { Vacuum aspirator or D \& C kit } \\
\text { (with speculum) }\end{array}$ & 73.3 & 4.5 & 22.3 \\
\hline Neonatal bag and mask & 79.9 & 5.1 & 15.0 \\
\hline Infant weighting scale & 77.6 & 6.9 & 15.5 \\
\hline Delivery Bed & 81.5 & 5.5 & 13.1 \\
\hline Blank Partograph & 82.3 & 8.9 & 8.9 \\
\hline Disposable Latex/Other Gloves & 82.8 & 5.4 & 11.8 \\
\hline Delivery Pack & 76.7 & 6.6 & 16.7 \\
\hline $\begin{array}{l}\text { Suction } \\
\text { extractor) }\end{array}$ & 70.2 & 6.2 & 23.6 \\
\hline $\begin{array}{l}\text { Soap and running water/ } \\
\text { alcohol based hand rub }\end{array}$ & 71.4 & 7.7 & 20.9 \\
\hline $\begin{array}{l}\text { Mean Domain Score of Equipment } \\
( \pm \text { SD })\end{array}$ & $77.4(4.33)$ & $6.5(1.58)$ & $16.1(4.95)$ \\
\hline \multicolumn{4}{|l|}{ Medicines } \\
\hline $\begin{array}{l}\text { Antibiotic eye ointment for new-born } \\
\text { (Chloramphenicol 1\%) }\end{array}$ & 82.5 & 5.0 & 12.6 \\
\hline $\begin{array}{l}\text { Injectable antibiotic } \\
\text { Ceftriaxone) }\end{array}$ & 61.9 & 10 & 28.1 \\
\hline $\begin{array}{l}\text { Injectable Uterotonic } \\
\text { Oxytocin) }\end{array}$ & 71.3 & 8.5 & 20.2 \\
\hline
\end{tabular}




\begin{tabular}{|lccc|}
\hline Magnesium Sulphate (injectable) & 65.8 & 8.7 & 25.6 \\
$\quad$ Injectable Diazepam & 58.3 & 11.4 & 30.3 \\
$\quad \begin{array}{l}\text { IV Solution (Ringer Lactate) with } \\
\text { Infusion Set }\end{array}$ & 73.3 & 7.0 & 19.8 \\
$\quad \begin{array}{l}\text { Skin Disinfectant } \\
\text { (Other than Chlorhexidine) }\end{array}$ & 78.3 & 6.1 & 15.6 \\
$\begin{array}{l}\text { 7.1\% Chlorhexidine Solution } \\
\text { (Umbilical Cord Cleansing) }\end{array}$ & 78.3 & 6.1 & 15.6 \\
\hline
\end{tabular}

Readiness index scores of the facilities specific to services for caesarean delivery is presented in table 3. Among the selected health facilities $50.6 \%$ staffs of public health facilities are trained compared with private facilities $42.6 \%$ and NGO facilities $6.8 \%$. The status of staff trained in anaesthesia and guidelines for CEmOC were also high in public facilities $(49.1 \%$ and $84.2 \%)$ than those of private facilities (44.3\% and 5.3\%) and NGO facilities (6.6\% and $10.5 \%)$ respectively. Mean domain score for staff and guidelines for public health facilities $(61.9 \%)$ was high compared with private facilities $(22.4 \%)$ and NGO facilities (14.1\%). In public facilities the mean domain score for equipment was $54.8 \%$ and in private health facilities it was $38.9 \%$ and in NGO facilities it was $6.4 \%$. In terms of diagnostics facilities the mean domain score for public health facilities was high $52.5 \%$ than private health facilities $30.2 \%$ and NGO facilities $17.4 \%$. Considering the mean domain score of medicines public health facilities with $54.2 \%$ were in fair enough position of readiness index compared with private health facilities (34.3) and NGO facilities (11.5\%).

Table 3: Readiness Index Scores Specific to Services for Caesarean Delivery and Domain Scores by Facility

\begin{tabular}{|lccc|}
\hline Staff and Guidelines & $\begin{array}{c}\text { Public } \\
\text { Facilities } \\
(\mathbf{n = 1 3 3 8})\end{array}$ & $\begin{array}{c}\text { NGO } \\
\text { Facilities } \\
\mathbf{\%}(\mathbf{n = 1 3 0})\end{array}$ & $\begin{array}{c}\text { Private } \\
\text { Facilities \% } \\
(\mathbf{n = 1 3 2})\end{array}$ \\
\cline { 2 - 4 } Staff trained in surgery & 50.6 & 6.8 & 42.6 \\
$\quad$ Staff trained in anaesthesia & 49.1 & 6.6 & 44.3 \\
$\quad$ Guidelines for CEmOC & 84.2 & 10.5 & 5.3 \\
$\quad$ Staff trained in CEmOC & 63.5 & 14.1 & 22.4 \\
\hline $\begin{array}{l}\text { Mean Domain Index of Staff and } \\
\text { Guidelines }( \pm \text { SD) }\end{array}$ & $\mathbf{6 1 . 9}(\mathbf{1 6 . 2 4})$ & $\mathbf{9 . 5}(\mathbf{3 . 5 5})$ & $\mathbf{2 8 . 7}(\mathbf{1 8 . 4 7})$ \\
\hline $\begin{array}{l}\text { Equipment } \\
\text { Incubator }\end{array}$ & & & \\
\hline
\end{tabular}




\begin{tabular}{|c|c|c|c|}
\hline Resuscitation table & 61.5 & 7.3 & 31.2 \\
\hline Spinal needle & 54.5 & 6.3 & 39.2 \\
\hline Anaesthesia Equipment & 41.7 & 5.6 & 52.8 \\
\hline Oxygen & 57.4 & 6.3 & 36.3 \\
\hline $\begin{array}{l}\text { Mean Domain Index of Equipment } \\
( \pm \text { SD })\end{array}$ & $54.8(7.72)$ & $6.4(.61)$ & $38.9(8.30)$ \\
\hline \multicolumn{4}{|l|}{ Diagnostics } \\
\hline Blood typing & 46.9 & 27.8 & 25.3 \\
\hline Cross match testing & 58.0 & 6.9 & 35.1 \\
\hline $\begin{array}{l}\text { Mean Domain Index of Diagnostics } \\
( \pm \text { SD })\end{array}$ & $52.5(7.85)$ & $17.4(14.78)$ & $30.2(6.93)$ \\
\hline \multicolumn{4}{|l|}{ Medicines } \\
\hline Ceftriaxone Injection & 51.1 & 16.9 & 32.1 \\
\hline Metronidazole Injection & 49.2 & 12.6 & 38.2 \\
\hline Epinephrine Injection & 17.6 & 14.7 & 67.6 \\
\hline Lidocaine $5 \%$ Injection & 69.8 & 11.8 & 18.4 \\
\hline Injection Atropine Sulphate & 81.1 & 7.2 & 11.7 \\
\hline $\begin{array}{c}\text { Blood supply safety (Blood } \\
\text { screening) }\end{array}$ & 56.5 & 7.7 & 35.9 \\
\hline $\begin{array}{l}\text { Blood supply sufficiency } \\
\text { (Facility has run out of blood) }\end{array}$ & 54.2 & 9.3 & 36.4 \\
\hline $\begin{array}{l}\text { Mean Domain Index of Medicines } \\
( \pm \text { SD })\end{array}$ & $54.2(19.76)$ & $11.5(3.62)$ & $34.3(17.79)$ \\
\hline
\end{tabular}

The result of multiple linear regression for delivery (normal and caesarean) specific service readiness index by facility type, region and place of residence has been discussed in table 4 . In terms of health facility type, the service readiness score was significantly high in public facilities for normal delivery but low for caesarean delivery. The study found that compared to public facilities probability of availability and readiness score was 4.27 times lower for NGO facilities and 1.74 times lower for private facilities. However, private facilities readiness score for caesarean delivery was significantly higher than public facilities. There were no paramount differences in divisions except for lower caesarean deliveryspecific readiness noted in Sylhet (12.11), Mymensingh (3.96), and Chittagong (2.58) compared to Dhaka. Overall, the readiness index score for both type of delivery was low, with little heterogeneity across the divisions. Service readiness index score by place of residence showed that health facilities in rural areas were significantly far less ready to provide caesarean services than urban area. 
Table 4: Estimated Adjusted Odds Ratio (OR) Obtained from Multiple Logistic Regression for Service Readiness Index

\begin{tabular}{|lcccc|}
\hline & \multicolumn{2}{c}{ Normal Delivery } & \multicolumn{2}{c|}{ Caesarean Delivery } \\
\cline { 2 - 5 } & Adjusted OR & p-value & Adjusted OR & p-value \\
\cline { 2 - 5 } Health Facilities & & & & \\
Government & 1.00 & - & 1.00 & - \\
NGO Facilities & 4.27 & $<0.001$ & 3.70 & 0.005 \\
Private & 1.74 & 0.026 & 0.53 & 0.013 \\
Region & & & & \\
Dhaka & 1.00 & - & 1.00 & - \\
Barisal & 1.30 & 0.196 & 2.58 & 0.056 \\
Chittagong & 0.78 & 0.195 & 0.40 & 0.012 \\
Khulna & 1.57 & 0.053 & 0.88 & 0.753 \\
Rajshahi & 1.07 & 0.753 & 0.65 & 0.299 \\
Rangpur & 1.21 & 0.416 & 0.48 & 0.087 \\
Sylhet & 0.83 & 0.411 & 12.11 & 0.018 \\
Mymensingh & 0.68 & 0.115 & 3.96 & 0.084 \\
Place of Residence & & & & \\
Urban & 1.00 & - & 1.00 & - \\
Rural & 7.96 & $<0.001$ & 84.43 & $<0.001$ \\
\hline
\end{tabular}

\section{Discussion}

This study shows a better understanding of the extent to which delivery service readiness of health facilities varies within and across the divisions, geographical areas, and facility types in Bangladesh. Findings of this study reveal that service readiness score is high for public facilities for normal delivery while private facilities readiness score is higher for caesarean delivery. This result is not different from previous studies which manifested that readiness score for normal delivery was higher in public facilities and caesarean delivery rate was higher in private facilities (Singh, Hashmi, \& Swain, 2018). Although private facilities are less accessible by people compared to public facilities (Siddiqui \& Khandaker, 2007; Sikder et al., 2015). Consistent with other studies (Leslie, Spiegelman, Zhou, \& Kruk, 2017; Wang et al., 2019) our results indicate that public facilities readiness in terms of availability of trained staff, guideline, equipment, diagnosis, 
and medicine is higher compared to NGO facilities and private facilities for both normal and caesarean delivers. Similar findings were found in India and Vietnam where public facilities readiness scores were higher than other facilities (Defar et al., 2020; Mundodan, 2015).

In all facilities gaps were notable in terms medicines and diagnostics that is affecting the overall readiness index. This result is not different from previous studies where Medicines and diagnostics have been identified as major factors obstruct the readiness index (Kaur et al., 2019; O'Neill, Takane, Sheffel, AbouZahr, \& Boerma, 2013). The current study does not represent any major regional variation on preparedness of health facilities to offer services for normal and caesarean delivery. There are similarities in readiness index scores across the region for normal delivery yet lower readiness index scores are observed in Sylhet, Mymensingh and Chittagong compared to Dhaka. In line with our study previous study did not find any significant regional variation (Footman et al., 2015; Powell-Jackson, Macleod, Benova, Lynch, \& Campbell, 2015). However, these results may not always reflect the actual picture of quality of care. Considering all facility types of readiness to provide both normal and caesarean delivery at institutional level the readiness index shows significant rural-urban disparities. Findings of our study is congruent with previous study which showed health facilities in rural areas with limited number of amenities have low service readiness scores for both normal and caesarean deliveries (Wang et al., 2019).

The strength of the present study is it used a nationwide representative dataset of Bangladesh Health Facility Survey 2017 to assess the preparedness of health facilities for the institutional delivery care in Bangladesh. However, the limitation of the study was that it fails to explain the causality assumptions because the questionnaire of the survey did not include quality of delivery service. Furthermore, readiness of the health facility for delivery care was analysed in terms of care, such as observance to guidelines, level of trained staff, availability medicines, diagnostics and equipment all assessed using several survey questions that may somewhat compromise to decrease dimensionality.

\section{Conclusion}

The study identified better readiness score of health facilities for services related for normal delivery services particularly at the public health facilities whereas private facilities provide better service for caesarean delivery. Whereas NGO 
facilities had sub-optimal readiness for any delivery services. The readiness of services for caesarean delivery was higher in private health facilities compared to the public health facilities. There was significant geographical variation found in health facilities preparedness to provide comprehensive caesarean services. Delivery service preparedness of urban health facilities was far better than rural areas. Therefore, to ensure better delivery services in rural area government need to expand more programs for developing trained staff and provide non-financial incentives for the trained staffs. In addition, public hospitals should ensure standard quality of caesarean delivery so that exorbitant financial costs of the rural families minimized to some extent. To achieve institutional delivery related targets of $4{ }^{\text {th }}$ Health, Population, Nutrition Sector Program (HPNSP) by 2022 and Sustainable Development Goals (SDGs) by 2030 government of Bangladesh needs to strengthen the health system for delivery service by ensuring the number of qualified staff, training, provision of diagnosis and medicines to improve the overall readiness of health facilities. Findings of the study provides evidencebased information that would support policymakers and stakeholders in developing policies/programs and ensure equitable access to delivery health services. Thus, it is recommended to strengthen all facilities capacity through availability of necessary medicines to control post-partum haemorrhage and diagnostics facilities for identifying obstructed labour to ensure safe motherhood. To get the actual supply side picture of public facilities in terms of preparedness, further research on effective coverage of delivery care is a prerequisite. Research related to delivery care may focus on feasibilities and scalability of public-private partnership, such as through training of staff, improving supply of essential medicines and management of delivery services. Furthermore, more research is required on how to decentralize diagnostic centres in rural areas. On the other hand, research at policy level is required for identifying different non-financial incentive schemes that would encourage skilled persons to stay in rural areas.

\section{References}

Anjomshoa, M., \& Mousavi, S. M. (2014). Regional disparities in the distribution of health care facilities: building evidence for evidence-based policy making. Iranian Journal of Public Health, 43(7), 1020-1021.

Anwar, I., Kalim, N., \& Koblinsky, M. (2009). Quality of obstetric care in public-sector facilities and constraints to implementing emergency obstetric care services: evidence from high-and low-performing districts of Bangladesh. Journal of Health, Population and Nutrition, 27(2), 139-155. 
Assefa, L., Alemayehu, M., \& Debie, A. (2018). Magnitude of institutional delivery service utilization and associated factors among women in pastoral community of Awash Fentale district Afar Regional State, Ethiopia. BMC Research Notes, 11(1), 162-167.

De Bernis, L., Dumont, A., Bouillin, D., Gueye, A., Dompnier, J. P., \& Bouvier-Colle, M. H. (2000). Maternal morbidity and mortality in two different populations of Senegal: a prospective study (MOMA survey). BJOG: An International Journal of Obstetrics \& Gynaecology, 107(1), 68-74.

Defar, A., Getachew, T., Taye, G., Tadele, T., Getnet, M., Shumet, T., \& Tadesse, A. (2020). Quality antenatal care services delivery at health facilities of Ethiopia, assessment of the structure/input of care setting. BMC Health Services Research, 20, 1-9.

DGHS. (2020). Health Bulletin 2019 Dhaka,Bangladesh. Retrieved from www.dghs.gov.bd (Accessed on January 11, 2021)

Donabedian, A. (1969). Quality of care: problems of measurement. II. Some issues in evaluating the quality of nursing care. American Journal of Public Health and the Nations Health, 59(10), 1833-1836.

Ensor, T., Dave-Sen, P., Ali, L., Hossain, A., Begum, S. A., \& Moral, H. (2002). Do essential service packages benefit the poor? Preliminary evidence from Bangladesh. Health Policy and Planning, 17(3), 247-256.

Exavery, A., Kanté, A. M., Njozi, M., Tani, K., Doctor, H. V., Hingora, A., \& Phillips, J. F. (2014). Access to institutional delivery care and reasons for home delivery in three districts of Tanzania. International Journal for Equity in Health, 13(1), 1-11.

Footman, K., Benova, L., Goodman, C., Macleod, D., Lynch, C., Penn-Kekana, L., \& Campbell, O. (2015). Using multi-country household surveys to understand who provides reproductive and maternal health services in low-and middle-income countries: A critical appraisal of the Demographic and Health Surveys. Tropical Medicine \& International Health, 20(5), 589-606.

Gabrysch, S., \& Campbell, O. M. (2009). Still too far to walk: literature review of the determinants of delivery service use. BMC Pregnancy and Childbirth, 9(1), 1-18.

Gitobu, C., Gichangi, P., \& Mwanda, W. (2018). The effect of Kenya's free maternal health care policy on the utilization of health facility delivery services and maternal and neonatal mortality in public health facilities. BMC Pregnancy and Childbirth, 18(1), 77, 1-11.

Joarder, T., Chaudhury, T. Z., \& Mannan, I. (2019). Universal Health Coverage in Bangladesh: activities, challenges, and suggestions. Advances in Public Health, 2019.

Kaur, J., Franzen, S. R. P., Newton-Lewis, T., \& Murphy, G. (2019). Readiness of public health facilities to provide quality maternal and newborn care across the state of Bihar, India: a crosssectional study of district hospitals and primary health centres. BMJ Open, 9(7), e028370, 1-10.

Kitui, J., Lewis, S., \& Davey, G. (2013). Factors influencing place of delivery for women in Kenya: an analysis of the Kenya demographic and health survey, 2008/2009. BMC Pregnancy and Childbirth, 13(1), 1-10.

Leslie, H. H., Spiegelman, D., Zhou, X., \& Kruk, M. E. (2017). Service readiness of health facilities in Bangladesh, Haiti, Kenya, Malawi, Namibia, Nepal, Rwanda, Senegal, Uganda and the United Republic of Tanzania. Bulletin of the World Health Organization, 95(11), 738748.

Manthalu, G., Yi, D., Farrar, S., \& Nkhoma, D. (2016). The effect of user fee exemption on the utilization of maternal health care at mission health facilities in Malawi. Health Policy and Planning, 31(9), 1184-1192.

MOHFW. (2017). 4th Health, Population and Nutrition Sector Programme (4th HPNSP) Dhaka, Bangladesh. Retrieved from www.dghs.gov.bd (Accessed on January 11, 2021) 
Montagu, D., Yamey, G., Visconti, A., Harding, A., \& Yoong, J. (2011). Where do poor women in developing countries give birth? A multi-country analysis of demographic and health survey data. PloS One, 6(2), e17155, 1-8.

Moyer, C. A., Dako-Gyeke, P., \& Adanu, R. M. (2013). Facility-based delivery and maternal and early neonatal mortality in sub-Saharan Africa: a regional review of the literature. African Journal of Reproductive Health, 17(3), 30-43.

Mridha, M. K., Anwar, I., \& Koblinsky, M. (2009). Public-sector maternal health programmes and services for rural Bangladesh. Journal of health, population, and nutrition, 27(2), 124-138.

Muchie, K. F. (2017). Quality of antenatal care services and completion of four or more antenatal care visits in Ethiopia: a finding based on a demographic and health survey. BMC Pregnancy and Childbirth, 17(1), 1-7.

Mundodan, J. M. (2015). Structural quality of antenatal clinics in the public health sector in a northern district in Kerala, India. JM al Int J Community Med Public Heal, 2(4), 513-519.

Nguyen, H. T., Hatt, L., Islam, M., Sloan, N. L., Chowdhury, J., Schmidt, J.-O., . . . Wang, H. (2012). Encouraging maternal health service utilization: an evaluation of the Bangladesh voucher program. Social science \& medicine, 74(7), 989-996.

NIPORT, icddr,b, \& Measure Evaluation. (2017). Bangladesh Maternal Mortality Survey 2016: Preliminary Report. Dhaka, Bangladesh, and Chapel Hill, NC, USA: NIPORT, icddr,b, and MEASURE Evaluation.

NIPORT, icddr,b, \& Measure Evaluation. (2020a). Bangladesh Demographic and Health Survey 2017-18. Dhaka, Dhaka, Bangladesh, and Chapel Hill, NC, USA: NIPORT, icddr,b, and MEASURE Evaluation.

NIPORT, icddr,b, \& Measure Evaluation. (2020b). Bangladesh Health Facility Survey 2017. Dhaka, Bangladesh, and Chapel Hill, NC, USA: NIPORT, icddr,b, and MEASURE Evaluation.

O'Neill, K., Takane, M., Sheffel, A., Abou-Zahr, C., \& Boerma, T. (2013). Monitoring service delivery for universal health coverage: the Service Availability and Readiness Assessment. Bulletin of the World Health Organization, 91(12), 923-931.

Powell-Jackson, T., Macleod, D., Benova, L., Lynch, C., \& Campbell, O. M. (2015). The role of the private sector in the provision of antenatal care: a study of Demographic and Health Surveys from 46 low-and middle-income countries. Tropical Medicine \& International Health, 20(2), 230-239.

Savedoff, W. D., de Ferranti, D., Smith, A. L., \& Fan, V. (2012). Political and economic aspects of the transition to universal health coverage. The Lancet, 380(9845), 924-932.

Siddiqui, N., \& Khandaker, S. A. (2007). Comparison of services of public, private and foreign hospitals from the perspective of Bangladeshi patients. Journal of Health, Population and Nutrition, 25(2), 221-230.

Sikder, S., Labrique, A., Ali, H., Hanif, A. A. M., Klemm, R., Mehra, S., . . Christian, P. (2015). Availability of emergency obstetric care (EmOC) among public and private health facilities in rural northwest Bangladesh. BMC Public Health, 15(1), 1-14.

Singh, P., Hashmi, G., \& Swain, P. K. (2018). High prevalence of cesarean section births in private sector health facilities- analysis of district level household survey-4 (DLHS-4) of India. BMC Public Health, 18(1), 1-10.

Steenland, M., Robyn, P. J., Compaore, P., Kabore, M., Tapsoba, B., Zongo, A., . . . Fink, G. (2017). Performance-based financing to increase utilization of maternal health services: evidence from Burkina Faso. SSM-Population Health, 3, 179-184. 
United Nations. (2015). Transforming Our World: The 2030 Agenda for Sustainable Development Goals. Retrieved from https://sustainabledevelopment.un.org/post2015/transformingourworld (Accessed on January 11, 2021)

Wang, W., Mallick, L., Allen, C., \& Pullum, T. (2019). Effective coverage of facility delivery in Bangladesh, Haiti, Malawi, Nepal, Senegal, and Tanzania. PloS One, 14(6), e0217853.

WHO. (2015). Service Availability and Readiness Assessment (SARA). World Health Organisation:France.

Wichaidit, W., Alam, M.-U., Halder, A. K., Unicomb, L., Hamer, D. H., \& Ram, P. K. (2016). Availability and Quality of Emergency Obstetric and Newborn Care in Bangladesh. The American Journal of Tropical Medicine and Hygiene, 95(2), 298-306. 